\title{
TEMPORAL AND SPATIAL DISTRIBUTION CHARACTERISTICS OF RHIZOSPHERE ORGANIC ACIDS UNDER WATER LEVEL FLUCTUATIONS IN THREE TYPES OF LAKES IN CHINA
}

\author{
ZHAO, K. ${ }^{1,2^{*}}-$ WAN, X.1,2-ZHOU, B. H. ${ }^{1,2}-$ ZHANG, X. K. ${ }^{3}$ \\ ${ }^{1}$ School of Environments and Resource, Anqing Normal University, Anqing Anhui, P. R. China \\ ${ }^{2}$ Key Laboratory of Aqueous Environment Protection and Pollution Control of Yangtze River in \\ Anhui of Anhui Provincial Education Department, Anqing Anhui, P. R. China \\ ${ }^{3}$ Research Center of Aquatic Organism Conservation and Water Ecosystem Restoration in \\ University of Anhui Province, Anqing Normal University, Anqing Anhui, P. R. China \\ *Corresponding author \\ e-mail: zhaokuan@aqnu.edu.cn; phone: +86-138-6511-1656 \\ (Received 23 ${ }^{\text {rd }}$ Apr 2020; accepted $11^{\text {th }}$ Aug 2020)
}

\begin{abstract}
Organic acids are influenced by many factors, such as season variations, water levels, vegetation and others. In the study, the rhizosphere soils of lakeshore plants in Poyang Lake, Chaohu Lake and Wuchang Lake in China were sampled under different water level fluctuations, and the amounts of organic acids were measured. Water level fluctuations affect the temporal and spatial characteristics of rhizosphere organic acids. The annual average of the total amount of organic acids in the rhizosphere soil of lakeshore plants in Wuchang Lake was higher than that in the other lakes. The seasonal variations in the amounts of organic acids were the same in the three lakes. The total amounts of organic acids in the rhizosphere soils at high water level sites were higher than those in the low water level sites of the three lakes. The effects of the interactions of season variations and water level fluctuations on the amount of organic acids in the rhizosphere were significant. The results revealed that the lake types changed in response to anthropogenic influence; Wuchang Lake, as a quasi-natural lake, suffered from much more human pollutants than Chaohu Lake as a reservoir-like lake and Poyang Lake as an intermittent lake.
\end{abstract}

Keywords: rhizosphere soils, lake type, lakeshore, season variations

Abbreviations: ANOVA, Analysis of variance; CA, Citric acid; CHL, Chaohu lake; MA, Malic acid; MC, Moisture content; OA, Oxalic acid; PYL, Poyanghu lake; SA, Succinic acid; SOM, Soil organic matter; TA, Tartaric acid; TN, Total nitrogen; TP, Total phosphorus; ToA, Total amount of organic acids; WCL, Wuchanghu lake

\section{Introduction}

A suitable water level is an important factor for maintaining the structure, function and biological integrity of lake ecosystems (Coops et al., 2003; Wantzen et al., 2008; Leira and Cantonati, 2008). Water level fluctuations are defined as the differences or changes in the water level within a period of time and are influenced by many factors, such as the water storage capacity, rainfall, and human factors involved in dam, highway and railway construction (Beckmann et al., 2005; Wang et al., 2007). Water level fluctuations have an important influence on the diversity of aquatic organisms; many studies have shown the effect of water level fluctuations on the digestion and retention of pollutants, the stabilization of the lakeshore, the maintenance of the water self-purification capacity, and the support of regional biological communities (Naiman and Décamps, 1997; Venkatachalam et al., 2005). For instance, water level fluctuations were found to influence the mobilization and transformation of nutrients such as nitrogen, phosphorus 
and chlorophyll a, as well as the diversity of phytoplankton and zooplankton (Sherr et al., 2003; Zhang et al., 2013; Liu et al., 2018). However, few studies have focused on the relationship between water level fluctuations and the root-soil environment, especially the effect of water level fluctuations on organic acids in rhizosphere soil.

Low molecular weight organic acids, such as citric acid, oxalic acid, and malic acid, are three of the most active forms of carbon in the plant-rhizosphere-soil interface and have great importance in physiological and biochemical processes, such as microbiological activity, nutrient acquisition, and the detoxification of heavy metals (Bais et al., 2006; Keiluweit et al., 2015; Chen et al., 2017). Numerous studies have shown that the allocation, transformation and exudation characteristics of organic acids are important mechanisms in response to environmental stresses. For instance, the roots of dicotyledonous species such as lupine (Lupinus albus L.), rape (Brassica napus L.) and alfalfa (Medicago sativa L.) exuded large amounts of organic acids under phosphorus deficiency; this organic acid mobilizes the insoluble phosphorus compound in rhizosphere soils, which increases the release of inorganic phosphorus and promotes phosphorus uptake (Haichar et al., 2014; Zhao and Wu, 2014; Baetz and Martinoia, 2014). Lakeshore plant species such as umbrella sedge and Pistia stratiotes adapt to phosphorus deficient environments via the regulation of the composition and amount of root-exuded organic acids (Zhang et al., 2019a,b). The roots of three lakeshore plants, Canna indica, Zizania aquatic and S. warburgii Seemen exude many organic compounds, mainly low molecular weight organic acids and aromatic proteins in root exudations; furthermore, the amount of such exudates was found to have a positive correlation with the biomass of the three plants (Lu et al., 2009). The mangrove Kandelia candel exudes high amounts of formic acid, butyric acid, malic acid, citric acid and lactic acid, and these low molecular weight organic acids increased the release of available heavy metals in wetland sediments (Lu et al., 2007). The composition and amount of organic acids in rhizosphere soils via root exudation can directly influence many biological processes in the rhizosphere-soilplant interface under environmental stresses (López-Bucio et al., 2000; Zhao and Wu, 2018). Therefore, investigation of the composition and amount of organic acids in rhizosphere soils of lakeshore plants will provide important information on nutrient acquisition, heavy metal detoxification and plant growth.

In the present study, the composition and amount of organic acids under different water level fluctuations in different seasons were investigated in the rhizosphere soils of lakeshore plants in three different lakes in the lower-middle reaches of the Yangtze River basin of China. Furthermore, the effects of the physicochemical parameters of the rhizosphere soils on the amounts of organic acids were analyzed, and the responses of organic acids in different lakes under different water level fluctuations were investigated.

\section{Materials and Methods}

\section{Study areas}

Three lakes, Poyang Lake (PYL), Chaohu Lake (CHL) and Wuchang Lake (WCL), in the middle and lower reaches of the Yangtze River that are affected by human disturbance were investigated (Fig. 1). PYL is located in Jiangxi Province, and CHL and WCL are located in Anhui Province. The three lakes are at relatively low elevations. CHL and WCL are regulated by the Yuxi and Wanhe sluices, which were constructed as a consequence of human disturbance, and the water surface areas of PYL have been greatly reduced. The climate of three lakes is a typical subtropical monsoon climate characterized by hot and 
rainy summers and cold and dry winters. The high temperature period is concentrated in July and August, the rainy season is from April to June, and the cold season occurs in January and February. The annual precipitation and annual air temperature at PYL, CHL and WCL are $1600.0 \mathrm{~mm}, 995.7 \mathrm{~mm}$ and $1299.6 \mathrm{~mm}$, and $17.2^{\circ} \mathrm{C}, 16.1{ }^{\circ} \mathrm{C}$ and $16.5^{\circ} \mathrm{C}$, respectively (Zhang, 2013; Zhang et al., 2018).

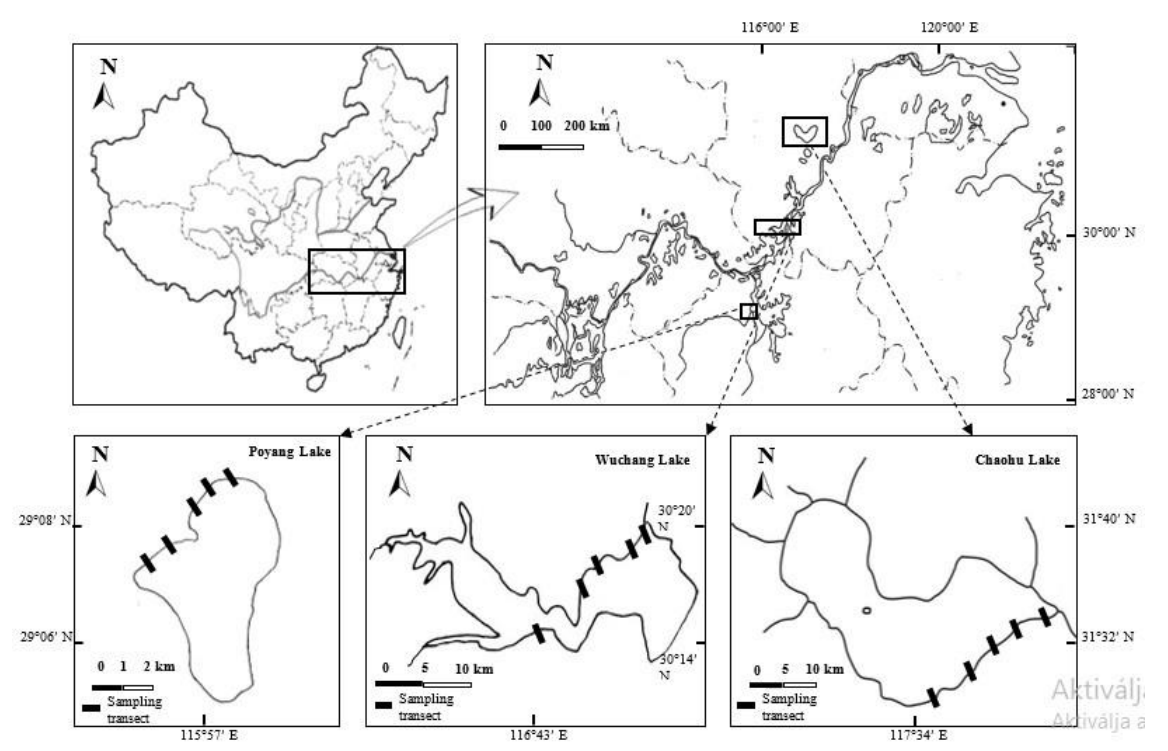

Figure 1. Study area and soil sampling sites of three lakes

PYL with a mean bottom elevation is $14.67 \mathrm{~m}$ amsl, and the water levels are low and stable with a mean water depth of less than $1.0 \mathrm{~m}$. The mean bottom elevation of CHL is 5.0-6.0 $\mathrm{m}$ above mean sea level (amsl), and the water level is often maintained at 7.5-8.0 $\mathrm{m}$ amsl. The annual average water level of CHL was raised about $1.5 \mathrm{~m}$ after the building of the sluice (Zhang et al., 2014). The mean bottom elevation of WCL is $10.0 \mathrm{~m}$ amsl, and the water level is often controlled at $11.5 \mathrm{~m}$ amsl. The main uses of WCL are for aquaculture and flood control (Zhang et al., 2016). The other limnological parameters of the three lakes are shown in Table 1.

Table 1. Limnological parameters of the three lakes. Note: Data are from Wang and Dou (1998), Zhang (2013), and Zhang et al. (2018)

\begin{tabular}{c|c|c|c}
\hline & Poyang Lake & Chaohu Lake & Wuchang Lake \\
\hline Area $\left(\mathrm{km}^{2}\right)$ & 30 & 769.6 & 100.5 \\
Mean water depth $(\mathrm{m})$ & 0.70 & 2.69 & 3.43 \\
Maximum water depth $(\mathrm{m})$ & 4.43 & 3.77 & 4.31 \\
Annual precipitation $(\mathrm{mm})$ & 1600 & 995.7 & 1299.6 \\
Annual air temperature $\left({ }^{\circ} \mathrm{C}\right)$ & 17.2 & 16.1 & 16.5 \\
Recharge coefficient of lake & - & 12.0 & 10.8 \\
Catchment area $\left(\mathrm{km}^{2}\right)$ & - & 9258 & 1083.7 \\
Volume $\left(\mathrm{m}^{3}\right)$ & - & $20.7 \times 10^{8}$ & $3.45 \times 10^{8}$ \\
\hline
\end{tabular}

The floristic composition along the shores of the three lakes are significantly different (Zhang et al., 2015, 2016). The vegetations along the shores of CHL and PYL are relatively simple, and the dominant species of the lakeside zone near CHL is mainly 
Cynodon dactylon, while Carex sp. is the dominant species in PYL. The floristic composition along the shore of WCL are relatively diverse, with Cynodon dactylon and Carex sp. covering some of the area, and the wild emergent aquatic plant species Zizania latifolia having a large distribution area.

\section{Rhizosphere soil sampling}

The rhizosphere soils of the lakeshore plants around lakes that exhibited three different types of fluctuations were investigated in the summer of 2016 (August, Summer), the autumn of 2016 (November, Autumn), the winter of 2017 (February, Winter) and the spring of 2017 (May, Spring). The main vegetation that grew in the soil samples were Cynodon dactylon in CHL, Carex sp. in PYL, and Zizania latifolia in WCL. The sections with limited artificial interference were selected in the three lakes, the five typical sample points were evenly distributed throughout this section, ranging from the lowest perennial average water level to the highest perennial average water level of the lake, which were called 1, 2, 3, 4 and 5 successively. The distance between two adjacent sample points remained equal. According to the water level fluctuations of the three lake types in the normal hydrological year 2015, water levels in these lakes are higher in winter and spring, and low in late spring to early summer, which is opposite to the natural condition (Zhang et al., 2018). Therefore, the elevations of the sample points in PYL were $14.75 \mathrm{~m}$ (PYL1), $15.56 \mathrm{~m}$ (PYL2), $16.38 \mathrm{~m}$ (PYL3), $17.19 \mathrm{~m}$ (PYL4) and $18.00 \mathrm{~m}$ (PYL5). The elevations of the five sample points in CHL were $8.15 \mathrm{~m}$ (CHL1), $8.61 \mathrm{~m}$ (CHL2), $9.07 \mathrm{~m}$ (CHL3), $9.52 \mathrm{~m}$ (CHL4) and $9.98 \mathrm{~m}$ (CHL5). The elevations of the sample points in WCL were $10.82 \mathrm{~m}$ (WCL1), $11.52 \mathrm{~m}$ (WCL2), $12.22 \mathrm{~m}$ (WCL3), $12.91 \mathrm{~m}$ (WCL4) and $13.61 \mathrm{~m}$ (WCL5).

The rhizosphere soil samples were randomly collected in triplicate in the three different lakes owing to the obvious lakeshore plant layer. The soil samples were collected always at the same site, the sampling sites of WCL, CHL and PYL were shown in Figure 1.

The soils within $0.5 \mathrm{~cm}$ from the root system were collected after excavating the roots and the aboveground parts of plants following the method described by Gollany et al. (1997), and the rhizosphere soil samples were divided into two parts.

One part was stored at $-24^{\circ} \mathrm{C}$ as fresh soil. The other part was dried and sieved through $2 \mathrm{~mm}$ mesh, and the soil physicochemical parameters, such as $\mathrm{pH}$, moisture content (MC), soil organic matter (SOM), total nitrogen (TN) and total phosphorus (TP), were determined. The $\mathrm{pH}$ and $\mathrm{MC}$ were measured by the potentiometric method and the ovendrying method, respectively; SOM was measured by the $\mathrm{K}_{2} \mathrm{Cr}_{2} \mathrm{O}_{7}$ titration method; the TN and TP contents were measured using the Kjeldahl method and molybdenum blue colorimetry, respectively (Lu, 2000).

\section{Extraction and purification of organic acids in rhizosphere soils}

A total of $5 \mathrm{~g}$ of fresh rhizosphere soil samples with the root chips, residues and others large particulate matter removed were placed in a $50 \mathrm{~mL}$ Erlenmeyer flask, and $25 \mathrm{~mL}$ $0.1 \% \mathrm{H}_{3} \mathrm{PO}_{4}$ extracted solution was added. The soils and the extracted solution were mixed with a glass rod, the mixed soil solution was oscillated for $2 \mathrm{~h}$; then, the mixture was transferred to a $50 \mathrm{~mL}$ centrifuge tube. The tube underwent centrifugation at $10000 \mathrm{r}$ $\mathrm{min}^{-1}$ for $10 \mathrm{~min}$; then, the supernatant was collected and passed through a $0.22 \mu \mathrm{m}$ water phase filtration membrane. 
The solutions containing organic acids were collected and passed through a cation exchange column $(12 \mathrm{~mm} \times 15 \mathrm{~mm})$ filled with $5 \mathrm{~g}$ of Amberlite IR-120B resin $\left(\mathrm{H}^{+}\right.$form, Alfa Co.). Afterward, these solutions were passed through an anion exchange column $(12 \mathrm{~mm} \times 15 \mathrm{~mm})$ filled with $3 \mathrm{~g}$ of Dowex $1 \times 8$ resin $\left(100\right.$ mesh to $200 \mathrm{mesh} ; \mathrm{OH}^{-}$ form; Acros Co.). The solutions were evaporated under rotary conditions of $40{ }^{\circ} \mathrm{C}$ after steaming to nearly dry, and the residue was obtained in $1 \mathrm{~mL}$ water for a quick rhizosphere soil sample test.

\section{Determination of the amounts of organic acids in rhizosphere soils}

The amounts of organic acids, including oxalic acid (OA), citric acid (CA), malic acid (MA), tartaric acid (TA) and succinic acid (SA), in the rhizosphere soils of the three lakes were analyzed by Waters Acquity H-Class ultra-performance liquid chromatography coupled with a four element pump system, automatic injection system, ultraviolet detector system, solvent system and chromatography column system (Zhao et al., 2019). The standard samples of OA, CA, MA, TA and SA were obtained from Sigma-Aldrich-Fluka (ref. 02288, 27488, 75688, 251380, and S7501, respectively). The concrete analytical conditions were the following: chromatography column, BEH C18 column $(2.1 \mathrm{~mm}$ i.d. $\times 500 \mathrm{~mm}, 1.7 \mu \mathrm{m}$ ); eluent solution, $10 \mathrm{mM} \mathrm{KH}_{2} \mathrm{PO}_{4}$ solution (adjust $\mathrm{pH}$ to $2.20 \pm 0.10$

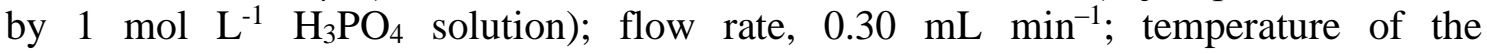
chromatography column, $30{ }^{\circ} \mathrm{C}$ and injection volume, $1 \mu \mathrm{L}$. The eluent solution and analyte were filtered using a $0.22 \mu \mathrm{m}$ membrane and then ultrasonically degassed before use.

\section{Statistical analysis}

All experiments were performed in triplicate with the same treatment independently replicated. Statistical analyses of data were carried out by one-way ANOVA, two-way ANOVA and bivariate correlations. Significance was assigned at the $p<0.05$ level with Duncan's test. All analyses were conducted using SPSS 17.0 (SPSS Inc., Chicago, IL, USA).

\section{Results}

\section{Soil physicochemical parameters}

The $\mathrm{pH}$ values were significantly different among the three lakes in the same season; the difference in $\mathrm{MC}$ was not significant in winter but exhibited significant differences in the other three seasons; SOM, TN and TP were not significantly different, except for SOM and TN, which were higher in PYL than in WCL and CHL in spring (Table 2). MC was not significantly different in the four seasons in WCL, while the other soil parameters were different (Table 2). The $\mathrm{pH}$ in autumn and winter was lower than that in spring and summer, while MC, SOM, TN and TP were not significantly different in CHL and PYL (Table 2).

\section{The total amount of organic acids in the rhizosphere soil of lakeshore plants in different seasons}

The total amount of organic acids (ToA), including OA, CA, MA TA and SA, in the rhizosphere soil of the lakeshore plants in winter was lower than that in the other three seasons in the three lakes, which was higher in summer than in the other three seasons in 
CHL and PYL and was highest in WCL (Fig. 2). The ToA in WCL was significantly higher than that in CHL and PYL during the same season (Fig. 2). The annual averages of the total amounts of organic acids in WCL, CHL and PYL were $2.783 \mathrm{mg} \mathrm{kg}^{-1}$, $1.668 \mathrm{mg} \mathrm{kg}^{-1}$, and $1.954 \mathrm{mg} \mathrm{kg}^{-1}$, respectively.

Table 2. The soil parameters at the sampling sites in Wuchanghu Lake, Chaohu Lake and Poyang Lake

\begin{tabular}{c|c|c|c|c|c}
\hline \multirow{2}{*}{ Lake name } & \multirow{2}{*}{ Soil parameters } & \multicolumn{4}{|c}{ Season } \\
\cline { 3 - 6 } & & Spring & Summer & Autumn & Winter \\
\hline \multirow{5}{*}{ Wuchang Lake } & $\mathrm{pH}$ & $7.22 \pm 0.80 \mathrm{Aa}$ & $7.37 \pm 0.30 \mathrm{Aa}$ & $6.05 \pm 0.18 \mathrm{Ab}$ & $5.800 \pm 0.30 \mathrm{Ab}$ \\
& $\mathrm{MC}(\%)$ & $22.13 \pm 4.88 \mathrm{Aa}$ & $24.41 \pm 4.60 \mathrm{Aa}$ & $26.06 \pm 5.04 \mathrm{Aa}$ & $29.47 \pm 18.29 \mathrm{Aa}$ \\
& $\mathrm{SOM}\left(\mathrm{mg} \mathrm{kg}^{-1}\right)$ & $1.03 \pm 0.22 \mathrm{Aa}$ & $1.01 \pm 0.48 \mathrm{Aa}$ & $1.63 \pm 0.58 \mathrm{Aab}$ & $2.57 \pm 1.93 \mathrm{Ab}$ \\
& $\mathrm{TN}\left(\mathrm{mg} \mathrm{kg}^{-1}\right)$ & $0.72 \pm 0.11 \mathrm{Aa}$ & $0.62 \pm 0.26 \mathrm{Aa}$ & $1.00 \pm 0.30 \mathrm{Aab}$ & $1.65 \pm 0.88 \mathrm{Ab}$ \\
& $\mathrm{TP}\left(\mathrm{mg} \mathrm{kg}^{-1}\right)$ & $0.44 \pm 0.09 \mathrm{Aa}$ & $0.33 \pm 0.09 \mathrm{Ab}$ & $0.32 \pm 0.05 \mathrm{Ab}$ & $0.42 \pm 0.08 \mathrm{Aab}$ \\
\hline \multirow{5}{*}{ Chaohu Lake } & $\mathrm{pH}$ & $8.68 \pm 0.20 \mathrm{Ba}$ & $8.29 \pm 0.15 \mathrm{Bb}$ & $7.58 \pm 0.05 \mathrm{Bc}$ & $7.68 \pm 0.11 \mathrm{Bc}$ \\
& $\mathrm{MC}(\%)$ & $18.67 \pm 4.16 \mathrm{Aa}$ & $21.13 \pm 4.07 \mathrm{Aa}$ & $18.31 \pm 5.46 \mathrm{Ba}$ & $16.60 \pm 2.84 \mathrm{Aa}$ \\
& $\mathrm{SOM}\left(\mathrm{mg} \mathrm{kg}^{-1}\right)$ & $0.84 \pm 0.34 \mathrm{Aa}$ & $1.96 \pm 1.54 \mathrm{Aa}$ & $1.08 \pm 0.81 \mathrm{Aa}$ & $1.44 \pm 1.28 \mathrm{Aa}$ \\
& $\mathrm{TN}\left(\mathrm{mg} \mathrm{kg}^{-1}\right)$ & $0.54 \pm 0.16 \mathrm{Aa}$ & $1.14 \pm 0.72 \mathrm{Aa}$ & $0.80 \pm 0.48 \mathrm{Aa}$ & $0.97 \pm 0.84 \mathrm{Aa}$ \\
& $\mathrm{TP}\left(\mathrm{mg} \mathrm{kg}^{-1}\right)$ & $0.58 \pm 0.24 \mathrm{Aa}$ & $1.12 \pm 1.19 \mathrm{Aa}$ & $0.69 \pm 0.51 \mathrm{Aa}$ & $1.16 \pm 1.18 \mathrm{Aa}$ \\
\hline \multirow{5}{*}{ Poyang Lake } & $\mathrm{pH}$ & $5.65 \pm 0.12 \mathrm{Ca}$ & $6.06 \pm 0.62 \mathrm{Ca}$ & $4.90 \pm 0.14 \mathrm{Cb}$ & $4.68 \pm 0.19 \mathrm{Cb}$ \\
& $\mathrm{MC}(\%)$ & $28.56 \pm 4.52 \mathrm{Ba}$ & $30.73 \pm 4.07 \mathrm{Ba}$ & $28.57 \pm 3.55 \mathrm{Aa}$ & $27.55 \pm 4.98 \mathrm{Aa}$ \\
& $\mathrm{SOM}\left(\mathrm{mg} \mathrm{kg}^{-1}\right)$ & $1.46 \pm 0.40 \mathrm{Ba}$ & $1.65 \pm 0.44 \mathrm{Aa}$ & $1.74 \pm 0.62 \mathrm{Aa}$ & $1.88 \pm 0.12 \mathrm{Aa}$ \\
& $\mathrm{TN}\left(\mathrm{mg} \mathrm{kg}^{-1}\right)$ & $1.05 \pm 0.26 \mathrm{Ba}$ & $1.17 \pm 0.22 \mathrm{Aa}$ & $1.13 \pm 0.38 \mathrm{Aa}$ & $1.3 \pm 0.17 \mathrm{Aa}$ \\
& $\mathrm{TP}\left(\mathrm{mg} \mathrm{kg}^{-1}\right)$ & $0.39 \pm 0.09 \mathrm{Aa}$ & $0.37 \pm 0.06 \mathrm{Aa}$ & $0.38 \pm 0.06 \mathrm{Aa}$ & $0.38 \pm 0.06 \mathrm{Aa}$ \\
\hline
\end{tabular}

Values are means $\pm \operatorname{SE}(n=3)$. The different capital letters indicate a significant difference in the three lakes in the same season at $\mathrm{p}<0.05$. The different lowercase letters indicate a significant difference in the four seasons at the same lake at $\mathrm{p}<0.05$. MC: moisture content; SOM: soil organic matter; TN: total nitrogen; TP: total phosphorus

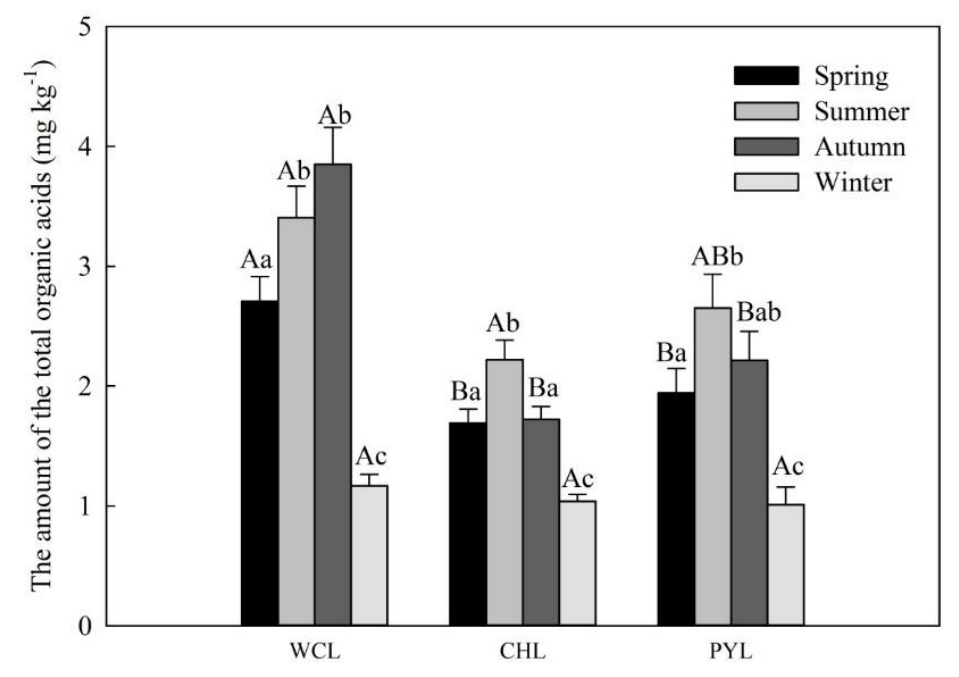

Figure 2. The variations in the total amount of organic acids in the rhizosphere soil of lakeshore plants in three lakes in different seasons. Note: Columns with bars indicate means \pm $S D(n=12)$. The different capital letters indicate a significant difference in the three lakes in the same season at $p<0.05$. The different lowercase letters indicate a significant difference in the four seasons under the same lake at p<0.05. PYL: Poyanghu Lake; CHL: Chaohu Lake; WCL: Wuchanghu Lake 
The effect of water level fluctuations on the characteristics of the ToA in the rhizosphere soil in different seasons

The seasonal variations in organic acids in the rhizosphere soil were significant at the different water levels in the three lakes, as shown in Fig. 3. At the different water level fluctuations, the ToA was between $0.607 \mathrm{mg} \mathrm{kg}^{-1}$ and $6.817 \mathrm{mg} \mathrm{kg}^{-1}$ in WCL, which was highest in summer, and lowest in winter, and the ToA at high water levels, such as at WCL3, WCL4, and WCL5, was higher than that at low water levels, such as WCL1 and WCL2 (Fig. 3). At the different water level fluctuations, the ToA was between $0.712 \mathrm{mg}$ $\mathrm{kg}^{-1}$ and $3.798 \mathrm{mg} \mathrm{kg}^{-1}$ in CHL. The ToA had was not significantly different in the sites with low water level fluctuations, including CHL1 and CHL2, in the different seasons; however, the ToA values were higher at the sites with high water level fluctuations, including CHL4 and CHL5. The ToA was the maximum at CHL4, which was two-fold higher than that at CHL1 in the all seasons except winter (Fig. 3). The ToA in the sites with different water level fluctuations in PYL was between $0.410 \mathrm{mg} \mathrm{kg}^{-1}$ and $3.909 \mathrm{mg}$ $\mathrm{kg}^{-1}$. The seasonal variations in the amount of organic acids were the following: summer $>$ autumn > spring > winter. The ToA at PYL4 was higher than that at the other sites.
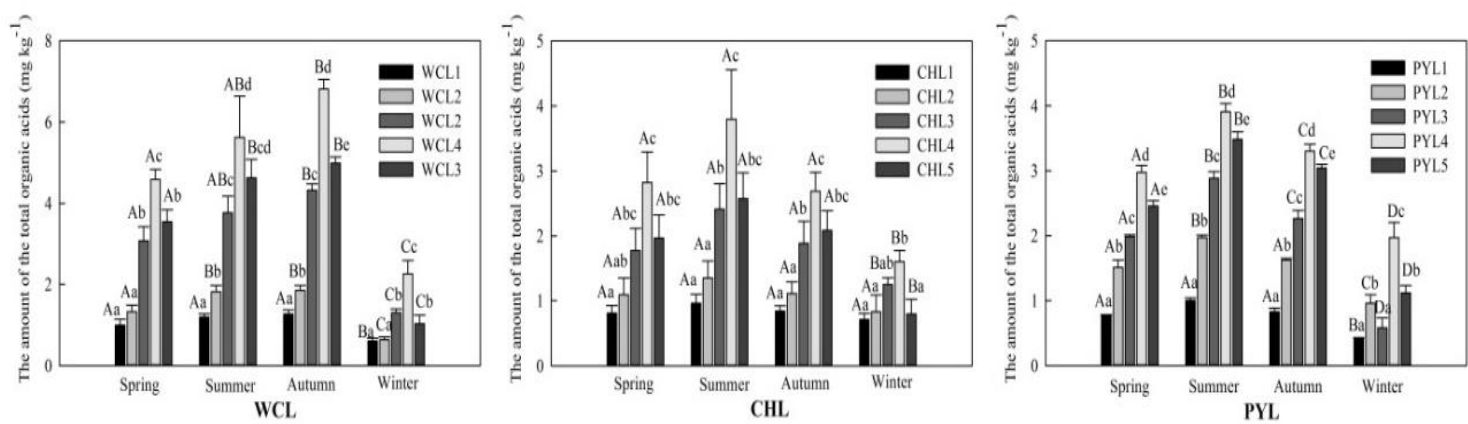

Figure 3. The effect of water level fluctuations on the characteristics of the total amounts of organic acids in rhizosphere soil in different seasons in the three lakes. Note: Columns with bars indicate means $\pm S D(n=3)$. The different capital letters indicate a significant difference in the four seasons under the same water level fluctuations in the same lakes at $p<0.05$. The different lowercase letters indicate a significant difference in the water level fluctuations in the same season in the same lakes at p <0.05. PYL: Poyanghu Lake; CHL: Chaohu Lake; WCL:

Wuchanghu Lake

The proportions of the five organic acids in the rhizosphere in different seasons in the three lakes

The contributions of OA, CA, MA, TA and SA to the ToA in the three lakes differed in the different seasons. The proportions of the five organic acids varied with season in WCL, and the proportion of CA increased, which accounted for $40 \%$ in winter (Fig. 4). The dominant organic acids were $\mathrm{CA}$ and $\mathrm{MA}$ in $\mathrm{CHL}$, and the proportion of CA and MA was over $60 \%$ in all four seasons (Fig. 4). CA, MA and SA were the dominant organic acids in the rhizosphere soils of PYL, accounting for more than $75 \%$ of the ToA, especially more than $90 \%$ in winter (Fig. 4). 

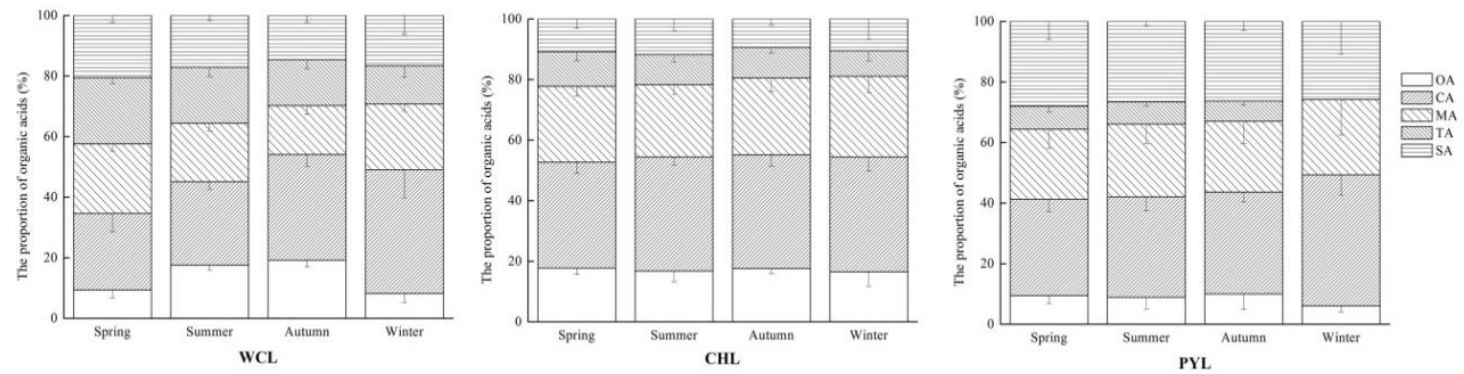

Figure 4. The proportions of the five organic acids in rhizosphere soil in different seasons in the three lakes. Note: Columns with bars indicate means $\pm S D(n=3)$. PYL: Poyanghu Lake;

CHL: Chaohu Lake; WCL: Wuchanghu Lake; OA: oxalic acid; CA: citric acid; MA: malic acid; TA: tartaric acid; SA: succinic acid

The interaction of seasonal variation and water level fluctuations with the characteristics of organic acids in rhizosphere soil

The effect of the interaction of the seasonal variation and water level fluctuations on the characteristics of the amounts of five organic acids and the ToA in rhizosphere soil of lakeshore plants in three lakes was significantly different based on the two-way ANOVA. The mean square value was between 0.002 and 4.839 , and the $\mathrm{F}$ value was between 5.602 and 123.355 in the three lakes $(p<0.001)$ (Table 3). The mean square value or $\mathrm{F}$ value of ToA in WCL was higher than that in PYL and CHL, which indicated the effect of interaction of seasonal variations and water level fluctuations on WCL was stronger than that on other two lakes (Table 3).

Table 3. The interaction of seasonal variations and water level fluctuations on the characteristics of organic acids in rhizosphere soil of lakeshore plants based on two-way ANOVA

\begin{tabular}{c|c|c|c|c|c}
\hline Lake name & Organic acids & Degree & $\begin{array}{c}\text { Mean square } \\
(\text { MS })\end{array}$ & F & $\begin{array}{c}\text { Significance }(\boldsymbol{p} \\
\text { value })\end{array}$ \\
\hline \multirow{5}{*}{ Wuchanghu Lake } & OA & 12 & 0.263 & 123.355 & $<0.001$ \\
& CA & 12 & 0.649 & 29.793 & $<0.001$ \\
& MA & 12 & 0.115 & 23.254 & $<0.001$ \\
& TA & 12 & 0.276 & 16.617 & $<0.001$ \\
& SA & 12 & 0.180 & 15.361 & $<0.001$ \\
& ToA & 12 & 4.839 & 47.289 & $<0.001$ \\
\hline \multirow{5}{*}{ Chaohu Lake } & OA & 12 & 0.069 & 5.800 & $<0.001$ \\
& CA & 12 & 0.175 & 5.129 & $<0.001$ \\
& MA & 12 & 0.073 & 14.791 & $<0.001$ \\
& TA & 12 & 0.013 & 5.863 & $<0.001$ \\
& SA & 12 & 0.019 & 5.602 & $<0.001$ \\
& ToA & 12 & 1.090 & 10.744 & $<0.001$ \\
\hline \multirow{5}{*}{ Poyanghu Lake } & OA & 8 & 0.002 & 13.366 & $<0.001$ \\
& CA & 8 & 0.035 & 17.620 & $<0.001$ \\
& MA & 8 & 0.065 & 30.201 & $<0.001$ \\
& TA & 8 & 0.002 & 7.860 & $<0.001$ \\
& SA & 8 & 0.022 & 10.523 & $<0.001$ \\
& ToA & 8 & 0.100 & 13.622 & $<0.001$ \\
\hline
\end{tabular}

OA: oxalic acid; CA: citric acid; MA: malic acid; TA: tartaric acid; SA: succinic acid; ToA: total amount of organic acids 


\section{The correlations between the amounts of organic acids and environmental factors in the three lakes}

Table 4 shows the correlations between the amounts of organic acids and physicochemical parameters of rhizosphere soils such as $\mathrm{pH}, \mathrm{MC}, \mathrm{SOM}$, TN and TP in the three lakes. The amount of one organic acid exhibited a linear correlation with the other organic acids and the ToA. The Pearson correlation coefficient $(\mathrm{R})$ ranged from 0.502 to 0.963 in the rhizosphere soils of lakeshore plants in the three lakes $(p<0.01)$. The soil parameters had different influences on the amount of organic acids in the rhizosphere soils of lakeshore plants in the three different lakes. There were no significant differences between the amounts of five organic acids or the ToA and MC, SOM, TN and $\mathrm{TP}$, except for the significant difference between TN and OA $(p<0.05)$. There were highly negative linear correlations between the individual organic acids or the ToA and $\mathrm{pH}$ $(p<0.01)$, except for the nonsignificant difference between TA and $\mathrm{pH}(p>0.05)$ in PYL. In CHL, the soil physicochemical parameters included $\mathrm{pH}, \mathrm{MC}$ and $\mathrm{SOM}$, and the individual organic acids or the ToA exhibited significant differences. The differences between the individual organic acids or the ToA and TN were highly significant $(p<0.01)$, except for the nonsignificant difference between TA or SA and TN $(p>0.05)$. Meanwhile, there was no significant difference between the individual organic acids or the ToA and TP $(p>0.05)$, except for the highly significant differences between OA and TP $(p<0.01)$. In WCL, the soil physicochemical parameters, including MC, SOM, TN and TP, exhibited a negative linear correlation with the individual organic acids or the ToA $(p<0.01)$, while $\mathrm{pH}$ had an influence on the amounts of MA, TA and SA.

Table 4. The Pearson correlation coefficients between the amounts of organic acids and soil physicochemical parameters of rhizosphere soils in Poyang Lake, Chaohu Lake and Wuchang Lake

\begin{tabular}{|c|c|c|c|c|c|c|c|c|c|c|c|}
\hline & & CA & MA & TA & SA & ToA & pH & MC & SOM & TN & TP \\
\hline \multirow{6}{*}{$\begin{array}{l}\text { Poyang } \\
\text { Lake }\end{array}$} & OA & $0.739 * *$ & $0.722 * *$ & $0.904 * *$ & $0.769 * *$ & $0.827 * *$ & $-0.502 * *$ & 0.075 & -0.219 & $-0.290 *$ & -0.106 \\
\hline & $\mathrm{CA}$ & 1 & $0.864 * *$ & $0.837 * *$ & $0.892 * *$ & $0.959 * *$ & $-0.381 * *$ & -0.015 & 0.086 & -0.096 & -0.014 \\
\hline & MA & & 1 & $0.818^{* *}$ & $0.841 * *$ & $0.942 * *$ & $-0.372 * *$ & -0.012 & -0.059 & -0.242 & 0.020 \\
\hline & TA & & & 1 & $0.749 * *$ & $0.877 * *$ & -0.270 & 0.006 & 0.111 & -0.017 & -0.031 \\
\hline & SA & & & & 1 & $0.951 * *$ & $-0.513 * *$ & 0.068 & 0.009 & -0.164 & -0.046 \\
\hline & ToA & & & & & 1 & $-0.465^{* *}$ & 0.026 & -0.017 & -0.195 & -0.019 \\
\hline \multirow{6}{*}{$\begin{array}{c}\text { Chaohu } \\
\text { Lake }\end{array}$} & OA & $0.822 * *$ & $0.757 * *$ & $0.636^{* *}$ & $0.526 * *$ & $0.895 * *$ & $-0.278 * *$ & $0.230 * *$ & $0.458 * *$ & $0.375^{* *}$ & $0.205 * *$ \\
\hline & $\mathrm{CA}$ & 1 & $0.853^{* *}$ & $0.619 * *$ & $0.578 * *$ & $0.963 * *$ & $-0.287 * *$ & $0.341 * *$ & $0.427 * *$ & $0.314 * *$ & 0.124 \\
\hline & MA & & 1 & $0.620 * *$ & $0.502 * *$ & $0.923 * *$ & $-0.269 * *$ & $0.386^{* *}$ & $0.460 * *$ & $0.331 * *$ & 0.096 \\
\hline & $\mathrm{TA}$ & & & 1 & $0.508 * *$ & $0.720 * *$ & $-0.403 * *$ & $0.452 * *$ & $0.208^{* *}$ & 0.127 & -0.109 \\
\hline & SA & & & & 1 & $0.649 * *$ & $-0.337 * *$ & $0.430 * *$ & $0.154^{*}$ & 0.028 & -0.106 \\
\hline & ToA & & & & & 1 & $-0.330 * *$ & $0.390 * *$ & $0.449 * *$ & $0.325^{* *}$ & 0.105 \\
\hline \multirow{6}{*}{$\begin{array}{c}\text { Wuchang } \\
\text { Lake }\end{array}$} & OA & $0.827 * *$ & $0.693 * *$ & $0.788 * *$ & $0.760 * *$ & $0.881 * *$ & 0.013 & $-0.209^{* *}$ & $-0.228 * *$ & $-0.332 * *$ & $-0.557 * *$ \\
\hline & $\mathrm{CA}$ & 1 & $0.800^{* *}$ & $0.827 * *$ & $0.822 * *$ & $0.947 * *$ & -0.135 & $-0.357 * *$ & $-0.180 *$ & $-0.235^{* *}$ & $-0.477 * *$ \\
\hline & MA & & 1 & $0.913 * *$ & $0.878 * *$ & $0.913 * *$ & $-0.196 * *$ & $-0.457 * *$ & $-0.342 * *$ & $-0.415^{* *}$ & $-0.337 * *$ \\
\hline & TA & & & 1 & $0.890 * *$ & $0.946^{* *}$ & $-0.185^{*}$ & $-0.367 * *$ & $-0.317 * *$ & $-0.416^{* *}$ & $-0.388 * *$ \\
\hline & SA & & & & 1 & $0.929 * *$ & $-0.157^{*}$ & $-0.373 * *$ & $-0.295 * *$ & $-0.376^{* *}$ & $-0.372 * *$ \\
\hline & ToA & & & & & 1 & 0.053 & $-0.379 * *$ & $-0.278 * *$ & $-0.363 * *$ & $-0.469 * *$ \\
\hline
\end{tabular}

OA: oxalic acid; CA: citric acid; MA: malic acid; TA: tartaric acid; SA: succinic acid; ToA: total amount of organic acids; MC, soil moisture content; SOM, soil organic matter; TN, total nitrogen; TP, total phosphorus. $* *$ indicates a significant difference at $\mathrm{p}<0.01$; * indicates a significant difference at $\mathrm{p}<0.05$ 


\section{Discussion}

\section{The influence of lake types on the amount of organic acids}

According to the different water level fluctuation patterns, the lakes in this study area could be divided into three types (Zhang, 2013). WCL is a quasi-natural fluctuating lake, which includes most lakes and some barrier lakes, and the water level fluctuations are similar to those of the Yangtze River. CHL is a reservoir-like fluctuating lake, which is mainly obstructed by other lakes and maintains a high water level all year round. The water level decreases due to irrigation or flood storage from April to June. PYL is an intermittent fluctuating lake, which is similar to floodplains and maintains stable low water levels most of the time, except in the high water level period at the Yangtze River trunk stream.

The composition and content of organic acids in the rhizosphere soil of the different lakes were different, and the annual average values of the ToA varied greatly. The annual average ToA in WCL was higher than that in PYL and CHL, which indicated that the carbon storage capacity in the rhizosphere soil of the quasi-natural lake wetland was higher than that in the intermittent lake and reservoir-like lake. The amount of organic acids in rhizosphere soils responded to the carbon storage and transformation capacities (Jones et al., 2009; Kuzyakov and Razavi, 2019). Due to the limited variations in the water level fluctuations and limited anthropogenic impacts, the carbon storage capacity in the rhizosphere soils of the WCL was higher than that in the CHL and PYL. CHL, as a reservoir-like lake, has a large amount of runoff, and the water that is stored in the lake is not enough to meet the demands because of the large amount of industrial and agricultural water consumption in the region, leading to the loss of carbon in rhizosphere soils. Hence, the annual average organic acid values were low in this lake. Furthermore, the dominant plant species and their distribution in the three lakes influenced the amount of organic acid in the rhizosphere. Zizania latifolia, as the dominant species in WCL, had the maximum biomass; Carex sp., as the dominant species in PYL had intermediate biomass, and the biomass of Cynodon dactylon, as the dominant species in CHL, was minimal (Zhang et al., 2018). The photosynthetically fixed carbon increased as the biomasses of these annual or biennial herbaceous plants increased. The carbon transformation increased from the aboveground parts (leaf, stem) to the belowground parts (root), resulting in an increase in root-exuded organic acids in the rhizosphere soils, which explained the higher ToA in the rhizosphere of quasi-natural lakes such as WCL than in the other two types of lakes.

\section{The variational characteristics of the amount of organic acids under water level fluctuations in four seasons}

The effects of seasonal variations on the amount of organic acids in the rhizosphere soil were evident, and the effects were irrelevant of the lake type. The amounts of organic acids were higher in summer and autumn than in spring and winter in the three lakes, resulting from the rapid growth and strong photosynthesis of wetland plants in summer and autumn, when plant roots exuded much more organic acids to rhizosphere soils. Due to the weak photosynthesis and low water level, the organic acid storage in the rhizosphere soil was low in winter (Wu and Zhao, 2013).

The amounts of organic acids at the sites with different water level fluctuations were different, and these were not related to the lake type. The amounts of ToA were higher at the sites with high water level fluctuations than that with low water level fluctuations. 
These differences not only were relevant to the above-mentioned factors, such as photosynthesis and biomass, but also may be related to other factors, such as the soil sample location and root morphology. Previous studies have shown that the root morphological parameters such as root length, root density, root volume, and root surface area at the sites with low water fluctuations were lower than those at sites with moderate and high water fluctuation levels (Zhang et al., 2018). These findings were consistent with the variation characteristics of organic acids in rhizosphere soils in this study. The root morphological parameters were positively correlated with the amount of organic acids in the rhizosphere soils of lakeshore plants. When the root morphological parameters were high, much more root organic acids were exuded into the rhizosphere soils.

\section{The differences in dominant organic acids}

The dominant types of organic acid were different in the three lakes. These were CA, MA and SA in PYL and CA and MA in CHL. In WCL, the distributions of the five organic acid contents were average, and only the CA content was higher in the high water level area. CA is the dominant organic acid among the three lakes in our study, which is the main organic acid in the Krebs cycle, not only accumulates in plant organs and tissue, but also is released into the rhizosphere via root exudates (Sweetlove et al., 2010; Araújo et al., 2012; Yu et al., 2017).

\section{The correlation between the amount of organic acids and the soil physicochemical parameters}

There were significant positive correlations among the amounts of organic acids in the three lakes, which indicated that a single organic acid was not exuded into soils, while multiple organic acids exuded simultaneously into the rhizosphere soil through the plasma membrane via diffusion and anion channels (Ryan et al., 2001; Adeleke et al., 2017; Silva and Lambers, 2020). There was a negative correlation between the amount of organic acids and $\mathrm{pH}$, which indicated that an increase in the amount of organic acids led to an increase in $\mathrm{H}^{+}$release, decreasing the $\mathrm{pH}$; however, this condition did not change the adsorption sites. MC and SOM had the same influences on the amount of organic acids, which included no influence on the amount of organic acids in PYL, a positive influence in CHL, and a negative influence in CHL because of the different heights of the water level fluctuations. TN and TP, as indicators of pollution sources, had limited impacts on the release of organic acids in PYL and CHL because the two lakes were greatly affected by human activities and exhibited low release of organic acids. TN and TP exhibited significant negative correlations with the amount of organic acids in the rhizosphere soil of WCL, which indicated that an increase in the exogenous input of nitrogen and phosphorus decreased the amount of organic acids in the rhizosphere soil. Thus, WCL, as a quasi-natural lake, was greatly influenced by human activities, and this lake may be converted to another type of lake and lose the function of the natural wetlands.

\section{Conclusion}

The organic acids of rhizosphere soil in different types of lakes were influenced by many factors, such as season variations, water levels, vegetations and the soil 
environment. The annual average amount of the total organic acids in the rhizosphere soil in the quasi-natural WCL was higher than that in the intermittent PYL and reservoir-like CHL, which was related to the vegetation density, photosynthesis and root morphological parameters of WCL. The seasonal differences in the amounts of organic acids were independent of lake type, and the amount of organic acids in the three lakes in winter was lower than that in the other three seasons. The dominant organic acids were different, and CA was the dominant organic acid in the three lakes. The CA accumulation in plant tissue can promote the release into rhizosphere soil. There were positive correlations among the amounts of organic acids in the three lakes. $\mathrm{pH}$ exhibited a negative correlation with the amount of organic acids. MC and SOM had no effect on the amount of organic acids in PYL, a positive effect in CHL and a negative effect in WCL. TN and TP had a greater impact on the amount of organic acids in WCL than in PYL and CHL, which would lead to changes to WCL as a result of anthropogenic influence.

In future studies, it will be necessary to consider the following two points: first, quantitatively analyze the organic acids characteristics in plant-rhizosphere soil- aquatic environment, the carbon distribution and transfer of organic acids should be focused via stable carbon isotope tracer technology. Second, in order to better understand the function of organic acid in plants especially root-exuded organic acids, the heavy metal concentration, nutrition such as phosphorus and nitrogen, and microbial activities should be investigated in rhizosphere soil-aquatic environment, and discuss the influence of anthropogenic intake pollution source.

Acknowledgements. The authors are grateful to all the people who provided assistance in rhizosphere soil sampling and the measurement of the organic acids. The study was supported by the National Natural Science Foundation of China (Grant No. 41501028), the Key Science and Technology Program of Anhui Province (Grant No. 17030701057), the Natural Science Foundation of Anhui Province (Grant No. 1908085QD149), and the Key Natural Science Research Projects of Universities in Anhui Province (Grant No. KJ2018A0374).

\section{REFERENCES}

[1] Adeleke, R., Nwangburuka, C., Oboirien, B. (2017): Origins, roles and fate of organic acids in soils: A review. - South African Journal of Botany 108: 393-406.

[2] Araújo, W. L., Nunes-Nesi, A., Nikoloski, Z., Sweetlove, L. J., Fernie, A. R. (2012): Metabolic control and regulation of the tricarboxylic acid cycle in photosynthetic and heterotrophic plant tissues. - Plant Cell and Environment 35: 1-21.

[3] Baetz, U., Martinoia, E. (2014): Root exudates: the hidden part of plant defense. - Trends in Plant Science 19(2): 90-98.

[4] Bais, H. P., Weir, T. L., Perry, L. G., Gilroy, S., Vivanco, J. M. (2006): The role of root exudates in rhizosphere interactions with plants and other organisms. - Annual Review of Plant Biology 57(1): 233-266.

[5] Beckmann, M. C., Scholl, F., Matthaei, C. D. (2005): Effects of increased flow in the main stem of the River Rhine on the invertebrate communities of its tributaries. - Freshwater Biology 50(1): 10-26.

[6] Chen, Y., Wang, Y., Yeh, K. (2017): Role of root exudates in metal acquisition and tolerance. - Current Opinion in Plant Biology 39: 66-72.

[7] Coops, H., Beklioglu, M., Crisman, T. L. (2003): The role of water-level fluctuations in shallow lake ecosystems-workshop conclusions. - Hydrobiologia 506-509: 23-27.

[8] Gollany, H. T., Bloom, P. R., Schumacher, T. E. (1997): Rhizosphere soil-water collection by immiscible displacement-centrifugation technique. - Plant and Soil 188: 59-64. 
[9] Haichar, F. E. Z., Santaella, C., Heulin, T., Achouak, W. (2014): Root exudates mediated interactions belowground. - Soil Biology and Biochemistry 77: 69-80.

[10] Jones, D. L., Nguyen, C., Finlay, R. D. (2009): Carbon flow in the rhizosphere: carbon trading at the soil-root interface. - Plant and Soil 321: 5-33.

[11] Keiluweit, M., Bougoure, J. J., Nico, P. S., Pett-Ridge, J., Weber, P. K., Kleber, M. (2015): Mineral protection of soil carbon counteracted by root exudates. - Nature Climate Change 5(6): 588-595.

[12] Kuzyakov, Y., Razavi, B. S. (2019): Rhizosphere size and shape: Temporal dynamics and spatial stationarity. - Soil Biology and Biochemistry 135: 343-360.

[13] Leira, M., Cantonati, M. (2008): Effects of water-level fluctuations on lakes: an annotatedbibliography. - Hydrobiologia 613: 171-184.

[14] Liu, J., Jiang, T., Wang, F., Zhang, J. Z., Wang, D. Y., Huang, R. H., Yin, D. L., Liu, Z. Y., Wang, J. Z. (2018): Inorganic sulfur and mercury speciation in the water level fluctuation zone of the three gorges reservoir, China: the role of inorganic reduced sulfur on mercury methylation. - Environment Pollution 237: 1112-1123.

[15] López-Bucio, J., Nieto-Jacobo, M. F., Ramírez-Rodríguez, V., Herrera-Estrella, L. (2000): Organic acid metabolism in plants: from adaptive physiology to transgenic varieties for cultivation in extreme soils. - Plant Science 160: 1-13.

[16] Lu, R. S. (2000): Soil and Agriculture Chemical Analysis Methods. - Chinese Agricultural Science and Technology Press, Beijing. (in Chinese).

[17] Lu, H., Yan, C., Liu, J. (2007): Low-molecular-weight organic acids exuded by Mangrove (Kandelia candel (L.) Druce) roots and their effect on cadmium species change in the rhizosphere. - Environmental and Experimental Botany 61(2): 159-166.

[18] Lu, S. L., Hu, H. Y., Sun, Y. X., Yang, J. (2009): Study on the growth characteristics and root exudates of three wetlands plants at different culture conditions. - Environmental Science 30(7): 1901-1905. (in Chinese).

[19] Naiman, R. J., Décamps, H. (1997): The ecology of interfaces: riparian zones. - Annual Review of Ecology and Systematics 28: 621-658.

[20] Ryan, P. R., Delhaize, E., Jones, D. L. (2001): Function and mechanism of organic anion exudation from plant roots. - Annual Review of Plant Physiology and Plant Molecular Biology 52: 527-560.

[21] Sherr, E. B., Sherr, B. F., Wheeler, P. A., Thompson, K. (2003): Temporal and spatial variation in stocks of autotrophic and heterotrophic microbes in the upper water column of the central arctic ocean. - Deep-Sea Research Part I-Oceanographic 50(5): 557-571.

[22] Silva, L. C. R., Lambers, H. (2020): Soil-plant-atmosphere interactions: structure, function, and predictive scaling for climate change mitigation. - Plant and Soil, https://doi.org/10.1007/s11104-020-04427-1.

[23] Sweetlove, L. J., Beard, K. F. M., Nunes-Nesi, A., Fernie, A. R., Ratcliffe, R. G. (2010): Not just a circle: flux modes in the plant tca cycle. - Trends in Plant Science 15(8): 462470.

[24] Venkatachalam, A., Radhakrishnan, J., Yamaji, E. (2005): Impact of riparian buffer zones on water quality and associated management considerations. - Ecological Engineering 24: 517-523.

[25] Wang, S. M., Dou, H. S. (1998): Lakes of China. - Science Press, Beijing. (in Chinese).

[26] Wang, H. Z., Xu, Q. Q., Cui, Y. D., Liang, Y. L. (2007): Macrozoobenthic community of Poyang lake, the largest freshwater lake of china, in the Yangtze floodplain. - Limnology 8(1): 65-71.

[27] Wantzen, K. M., Rothhaupt, K. O., Mörtl, M., Cantonati, M., G-Tóth, L. S., Fischer, P. (2008): Ecological effects of water-level fluctuations in lakes: an urgent issue. Hydrobiologia 613: 1-4.

[28] Wu, Y. Y., Zhao, K. (2013): Root-exuded malic acid versus chlorophyll fluorescence parameters in four plant species under different phosphorus levels. - Journal of Soil Science and Plant Nutrition 13(3): 604-610. 
[29] Yu, G., Xiao, J., Hu, S., Polizzotto, M. L., Zhao, F., McGrath, S. P., Li, H., Ran, W., Shen, Q. (2017): Mineral availability as a key regulator of soil carbon storage. - Environmental Science and Technology 51(9): 4960-4969.

[30] Zhang, X. K. (2013): Water level fluctuation requirements of plants in the Yangtze floodplain lakes. - Dissertation of University of Chinese Academy of Sciences, Beijing (in Chinese).

[31] Zhang, Z., Wan, C., Zheng, Z. W., Hu, L., Feng, K., Chang, J. B., Xie, P. (2013): Plant community characteristics and their responses to environmental factors in the water level fluctuation zone of the three gorges reservoir in China. - Environ Science and Pollution Research 20(10): 7080-7091.

[32] Zhang, X., Liu, X., Wang, H. (2014): Developing water level regulation strategies for macrophytes restoration of a large river-disconnected lake, China. - Ecological Engineering 68: 25-31.

[33] Zhang, X., Liu, X., Wang, H. (2015): Effects of water level fluctuations on lakeshore vegetation of three subtropical floodplain lakes, China. - Hydrobiologia 747: 43-52.

[34] Zhang, X., Wan, A., Wang, H. L., Zhu, L. L., Yin, J., Liu, Z. G., Yu, D. P. (2016): The overgrowth of Zizania latifolia in a subtropical floodplain lake: changes in its distribution and possible water level control measures. - Ecological Engineering 89: 114-120.

[35] Zhang, X. K., Qin, H. M., Wang, H. L., Wan, A., Liu, G. H. (2018): Effects of water level fluctuations on root architectural and morphological traits of plants in lakeshore areas of three subtropical floodplain lakes in China. - Environ Science and Pollution Research 25(34): 34583-34594.

[36] Zhang, J. C., Wang, K. Q., Zhao, Y. Y., Duan, X., Liang, X. X. (2019a): Effects of phosphorus stress on root exudates of umbrella sedge in plateau wetland plants. Environmental Science and Technology 42(2): 17-24. (in Chinese).

[37] Zhang, J. C., Zhao, Y. Y., Duan, X., Liang, X. X. (2019b): Effects of phosphorus stress on root exudates of floating plant pistia stratiotes in plateau wetlands. - Environmental Chemistry 38(2): 385-394. (in Chinese).

[38] Zhao, K., Wu, Y. Y. (2014): Rhizosphere calcareous soil P-extraction at the expense of organic carbon from root-exuded organic acids induced by phosphorus deficiency in several plant species. - Soil Science and Plant Nutrition 60(5): 640-650.

[39] Zhao, K., Wu, Y. Y. (2018): Effect of Zn deficiency and excessive $\mathrm{HCO}_{3}{ }^{-}$on the allocation and exudation of organic acids in two Moraceae plants. - Acta Geochimica 37(1): 125-133.

[40] Zhao, K., Cao, J. J., Jin, B. S., Zhou, B. H., Zhang, X. K. (2019): A fast and simultaneous determination of Five organic acids in wetland soils by ultra-performance liquid chromatography. - Earth and Environment 47(4): 546-551. (in Chinese). 